\title{
Frequency of subclinical hypothyroidism in chronic kidney disease patients.
}

1. MBBS, FCPS

Senior Registrar Nephrology Rehman Medical Institute Peshawar.

2. MBBS, FCPS

Assistant Professor Nephrology Rehman Medical Institute Peshawar.

3. MBBS, FCPS

Associate Professor Medicine Ayub Teaching Hospital Abbottabad.

4. MBBS, FCPS

Consultant Medicine

Ayub Teaching Hospital Abbottabad.

5. MBBS

Medical Officer Internal Medicine Shaukat Khanum Hospital,

Peshawar

6. MBBS

House Officer

Ayub Teaching Hospital,

Abbottabad.



ABSTRACT... Objective: To determine the frequency of sub clinical hypothyroidism among chronic kidney disease patients in our population. Study Design: Descriptive Cross sectional study. Settings: Department of Nephrology, Khyber Teaching Hospital Peshawar. Period: February 2018 to September 2018. Material \& Methods: A total of 145 chronic kidney disease patients were included in this study. Thyroid function tests (TFT, s) were performed in all patients along with history and clinical examination. Sub clinical hypothyroidism was defined as high TSH (normal value 0.27-4.0 $\mu \mathrm{lU} / \mathrm{ml}$ ) and normal Free T47. (0.93 - $1.70 \mathrm{ng} / \mathrm{dl})$. Results: Our study shows that Mean age was 55 years with standard deviation \pm 2.83 . Eighty seven $(60 \%)$ patients were male and $58(40 \%)$ patients were female. Moreover, $25 \%$ patients had subclinical hypothyroidism. Conclusion: Our study concludes that the incidence of subclinical hypothyroidism in chronic kidney disease was found to be $25 \%$ in our population.

Key words: $\quad$ Chronic Kidney Disease, Subclinical Hypothyroidism.

Correspondence Address:

Dr. Talha Durrani

Shaukat Khanum Hospital,

Peshawar

Article received on:

14/10/2020

Accepted for publication:

$30 / 12 / 2020$

\section{INTRODUCTION}

Chronic kidney disease is a major health problem worldwide. ${ }^{1}$ Globally millions of patients are affected by it and is major cause of mortality and morbidity. ${ }^{2}$ It is divided into five stages. ${ }^{3}$ With higher stage of disease, the rate of mortality increase. ${ }^{4}$ There are many complication of chronic kidney disease as well. Some of which are anemia, cardiovascular disease, metabolic disorders, mineral bone disease. ${ }^{5}$

Among complications, there is an association of thyroid dysfunction with chronic kidney disease. Thyroid gland is one of important gland in the body and play pivotal role in regulating different body functions which include metabolism, proteinsynthesis, body development and also influence other hormone function. It secretes two important hormones namely triiodothyronine (T3) and thyroxine (T4). ${ }^{6}$ These hormones nearly affect every organ including kidney. In chronic kidney disease as the patient progresses to higher stage of disease, the prevalence of thyroid dysfunction increases. Thyroid hormone has protective role on renal functions and its replacement can reverse the change in the renal functions. ${ }^{7}$ Thyroid hormones have some important effect on renal physiology by which it increases renal blood flow and glomerular filtration rate. Hypothyroidism can reduce renal blood flow and glomerular filtration rate and vice versa. ${ }^{8}$

Recent data suggests a close relationship of thyroid dysfunction and chronic kidney disease. Different studies are published in different part of the world showing high prevalence of hypothyroidism in chronic kidney disease. Internationally, a study conducted shows a prevalence of $24.4 \%$ with subclinical hypothyroidism in chronic kidney disease. ${ }^{7}$ Another show a prevalence of $56 \%$ with hypothyroidism in chronic kidney disease. ${ }^{7,9} \mathrm{Na}$ tionally, a study by Asif et al shows a prevalence of $53.8 \%$ with subclinical hypothyroidm. ${ }^{10}$

Studies conducted in different parts of the world show different frequencies of subclinical 
hypothyroidism in chronic kidney disease patients. so the aim of our study is to find out the frequency of subclinical hypothyroidism in chronic kidney disease patients in Khyber Pukhtoonkhuwa (KPK) and to correlate it with the frequencies in other studies and to identify the problem early in the course of disease and give adequate treatment to prevent progression and also if found significant, can be addressed to the health authorities to plan future strategy for the problem.

\section{MATERIAL \& METHODS}

This study was descriptive cross-sectional study conducted in Nephrology department of Khyber teaching Hospital, Peshawar from February 2018 to September 2018. Non-probability consecutive sampling technique was used. Sample size was 145 using $24.4 \%$ prevalence of subclinical hypothyroidism in chronic kidney disease ${ }^{7}$, $95 \%$ confidence interval with more than $7 \%$ of error with help of WHO software for sample size determination. Our inclusion criteria included all patients with chronic kidney disease of age above 20 years and below 70 years both male and female. Exclusion criteria included all patients with established hypothyroidism before diagnosed as CKD, all critical patients, and those patients using anti thyroid drugs. These mentioned conditions act as confounders and if included in the study, could introduce bias in the study results. After getting approval from the hospital ethical and research committee all patients meeting the inclusion criteria were included in the study and data was collected. An informed written consent was taken from the patients for inclusion in the study.

All patients were worked up with detailed history, clinical examination. Blood samples taken were analyzed for thyroid function tests. Data was analyzed using Statistical Package for Social Sciences (SPSS) version 17 or higher version. Mean \pm standard deviation was calculated for continuous Variables like age, T4 and TSH level of patients. Frequency and percentages were calculated for qualitative variables like gender and subclinical hypothyroidism. Subclinical hypothyroidism was stratified among age and gender to see effect modifier. Post stratification chi-square test was applied keeping $p$-value less $\leq 0.05$ as significant. All these results were presented in the form of tables and charts.

\section{RESULTS}

This study was conducted at Nephrology department of Khyber teaching Hospital, Peshawar in which a total of 145 patients were observed to determine the frequency of subclinical hypothyroidism in chronic kidney disease patients in our population. Subclinical hypothyroidism was defined as high TSH (normal value 0.27-4.0 $\mu \mathrm{lU} / \mathrm{ml}$ ) and normal Free T4. (0.93 $-1.70 \mathrm{ng} / \mathrm{dl})$. The results were analyzed as:

Age distribution among 145 patients was analyzed as $22(15 \%)$ patients were in age range $31-40$ years, $32(22 \%)$ patients were in age range $41-50$ years, $43(30 \%)$ patients were in age range $51-60$ years, $48(33 \%)$ patients were in age range 51 60 years. Mean age was 55 years with standard deviation \pm 2.83 .

Gender distribution among 145 patients was analyzed as $87(60 \%)$ patients were male and $58(40 \%)$ patients were female.

Status of thyroid function among 145 patients was analyzed as all the patients had T4 range 0.93$1.70 \mathrm{ng} / \mathrm{dl}$. Whereas 109(75\%) patients had TSH range $\leq 0.27-4.0 \mu \mathrm{lU} / \mathrm{ml}$ and $36(25 \%)$ patients had TSH $>4.0 \mu \mathrm{lU} / \mathrm{ml}$. Mean TSH was $4 \mu \mathrm{lU} / \mathrm{ml}$ with standard deviation \pm 2.37 . (Table-l)

Subclinical hypothyroidism among 145 patients was analyzed as $36(25 \%)$ patients had subclinical hypothyroidism in CKD while 109(75\%) patients didn't had subclinical hypothyroidism in CKD. (Table-II)

Stratification of subclinical hypothyroidism with age and gender is given in Table-III and Figure-1. respectively. 


\begin{tabular}{|c|c|c|}
\hline \multicolumn{1}{|c|}{ T4 } & Frequency & Percentage \\
\hline $0.93-1.70 \mathrm{ng} / \mathrm{dl}$ & 145 & $100 \%$ \\
\hline$>0.93-1.70 \mathrm{ng} / \mathrm{dl}$ & 0 & $0 \%$ \\
\hline Total & 145 & $100 \%$ \\
\hline \multicolumn{1}{|c|}{ TSH } & Frequency & Percentage \\
\hline$\leq 0.27-4.0 \mu \mathrm{lU} / \mathrm{ml}$ & 109 & $75 \%$ \\
\hline$>4.0 \mu \mathrm{lU} / \mathrm{ml}$ & 36 & $25 \%$ \\
\hline Total & 145 & $100 \%$ \\
\hline
\end{tabular}

Table-I. Status of thyroid function test (T4 and TSH). $(n=145)$.

Mean T4 was $1.1 \mathrm{ng} / \mathrm{dl}$ with standard deviation \pm 1.12 , while Mean TSH was $4 \mu \mathrm{lU} / \mathrm{ml}$ with standard deviation \pm 2.37

\begin{tabular}{|l|c|c|}
\hline Hypothyroidism & Frequency & Percentage \\
\hline Yes & 36 & $25 \%$ \\
\hline No & 109 & $75 \%$ \\
\hline Total & 145 & $100 \%$ \\
\hline
\end{tabular}

Table-II. Subclinical Hypothyroidism. $(n=145)$.

\begin{tabular}{|l|c|c|c|c|c|}
\hline $\begin{array}{c}\text { Hypo- } \\
\text { thyroidism }\end{array}$ & $\begin{array}{c}\mathbf{3 1 - 4 0} \\
\text { years }\end{array}$ & $\begin{array}{c}41-50 \\
\text { years }\end{array}$ & $\begin{array}{c}\mathbf{5 1 - 6 0} \\
\text { years }\end{array}$ & $\begin{array}{c}\mathbf{6 1 - 7 0} \\
\text { years }\end{array}$ & Total \\
\hline Yes & 5 & 8 & 11 & 12 & 36 \\
\hline No & 17 & 24 & 32 & 36 & 109 \\
\hline Total & 22 & 32 & 43 & 48 & 145 \\
\hline
\end{tabular}

Table-III. Stratification of subclinical hypothyroidism W.R.T age. $(n=145)$

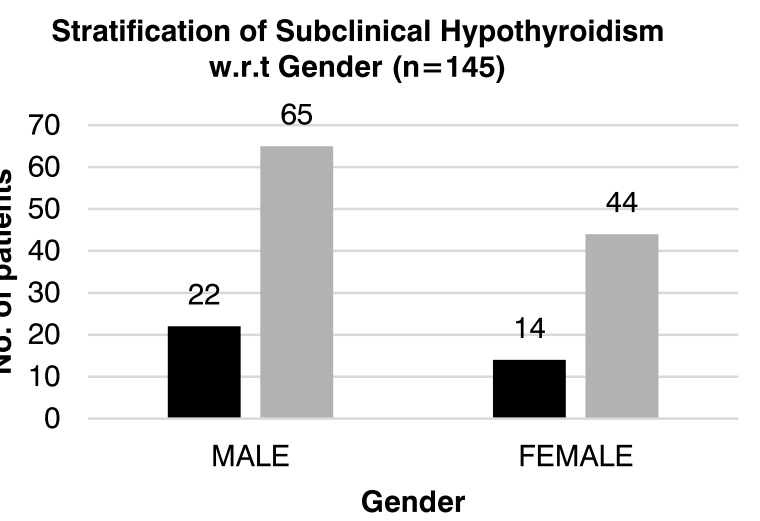

YES NO

Figure-1

Chi Square test was applied in which $P$ value was 0.8752

\section{DISCUSSION}

Chronic kidney disease is a silent global epidemic. The exact prevalence of CKD in Pakistan is not known, but given the fact that diabetes mellitus, which is the most common cause of CKD, is very common in Pakistan; therefore it is not surprising that CKD will be highly prevalent in Pakistan. ${ }^{11}$

We included 145 patients in our study of which 87 were males while 58 were females. Mean+SD of age was $55+2.83$. Twenty five percent patients had subclinical hypothyroidism in CKD.

Internationally, a study conducted shows a prevalence of $24.4 \%$ with subclinical hypothyroidism in chronic kidney disease. ${ }^{7}$ Another show a prevalence of $56 \%$ with hypothyroidism in chronic kidney disease. ${ }^{9}$ Nationally, a study by Asif et al shows a prevalence of $53.8 \%$ with subclinical hypothyroidism. ${ }^{10}$

Literature has reported that $4 \%$ to $10 \%$ of general population suffers from subclinical hypothyroidism ${ }^{11}$ and the prevalence is estimated to be higher in the elderly i.e up to $26 \% .{ }^{12}$ Similarly, numerous studies in the past showed that thyroid disorders were even more common in patients with CKD. ${ }^{7,13}$ In addition, some of these studies reported thyroid abnormalities in CKD patients have higher mortality and morbidity compared to those who have normal thyroid profile.,14 $\mathrm{A}$ number of factors are believed to cause this higher mortality; some of these include the presence of autoimmunity, deranged iodine metabolism and increased peripheral resistance.

Currently, more research is going on to determine the prevalence of hypothyroidism with regards to the stage of chronic kidney disease. In this regard Lo et al. recently reported that subclinical and clinical hypothyroidism was more common in patients with higher stage of kidney disease compared to others. They noted that the frequency of hypothyroidism was more than $20 \%$ in patients with eGFR $<60 \mathrm{ml} / \mathrm{min}$ per 1.73 $\mathrm{m} .{ }^{15,16}$ In our study the prevalence was found to be $25 \%$. The differences in our results may be due to that in Lo et al, the study population was much younger and total T4 levels assessment 
was done as opposed to FT4 levels.

Subclinical hypothyroidism has a number of etiological causes with autoimmune thyroid disease being the most common. Other less common causes include drugs, subacute thyroiditis, radiation thyroiditis, and postpartum thyroiditis. ${ }^{17-19}$ Subclinical hypothyroidism has been demonstrated to adversely affect the cardiac functioning. In addition, it is now reported that it may deteriorate the risk factors for ischemic heart disease especially hypertension and dyslipidemia. ${ }^{20,21}$

Our study was not without limitations. Firstly, our sample size was small and larger sample size is required to establish any relationship between hypothyroidism and chronic kidney disease. Secondly, we relied on eGFR which does not accurately measures the renal function and are thus subjected to errors. Thirdly, we could not identify and separate patients with sick euthyroidism and finally, we did not stratify our patients into different classes of CKD based on eGFR and thus did not correlate the frequency of hypothyroidism with the severity of CKD.

\section{CONCLUSION}

Our study concludes that the incidence of subclinical hypothyroism in chronic kidney disease was found to be reasonably high in our population. We therefore recommend that there should be high level of suspicion in considering the diagnosis of subclinical hypothyroidism in patients with CKD.

\section{Copyright $\subseteq 30$ Dec, 2020.}

\section{REFERENCES}

1. Fraser SDS, Roderick PJ, May CR, Mclntyre N, Mclntyre C, Fluck RJ, et al. Correction to: The burden of comorbidity in people with chronic kidney disease stage 3: A cohort study. BMC nephrology. 2020; 21(1):543.

2. Murton M, Goff-Leggett D, Bobrowska A, Garcia Sanchez $\mathrm{JJ}$, James G, Wittbrodt E, et al. Burden of chronic kidney disease by KDIGO categories of glomerular filtration rate and albuminuria: A systematic review. Advances in therapy. 2020.
3. Levey AS, Eckardt KU, Dorman NM, Christiansen $S L$, Cheung $M$, Jadoul $M$, et al. Nomenclature for kidney function and disease-executive summary and glossary from a Kidney Disease: Improving Global Outcomes (KDIGO) consensus conference. European heart journal. 2020.

4. Alshammari F, Alhazaa S, Althemery A, Alsabaan $\mathrm{F}$, AlGosaibi A, Alshammari $\mathrm{M}$, et al. Prevalence of hypothyroidism among chronic kidney disease patients in security force hospital (SFH) in Saudi Arabia. Journal of family medicine and primary care. 2019; 8(10):3313-7.

5. Llisterri JL, Mico-Perez RM, Velilla-Zancada S, Rodriguez-Roca GC, Prieto-Diaz MA, Martin-Sanchez $\mathrm{V}$, et al. Prevalence of chronic kidney disease and associated factors in the Spanish population attended in primary care: Results of the IBERICAN study. Medicina clinica. 2020.

6. Liu T, Guan Y, Li J, Mao H, Zhan Y. Thyroid dysfunction and cardiovascular events in patients with chronic kidney disease: A protocol of systematic review and meta-analysis. Medicine. 2020; 99(47):e23218.

7. Roy AS, Ahammed AU, Das SK, Asadujjaman M, Hossain $M B$, Salahuddin AZ, et al. Prevalence of subclinical hypothyroidism in hospitalized pre-dialysis patients with chronic kidney disease. Mymensingh medical journal: MMJ. 2020; 29(4):764-70.

8. Chandra A. The dilemma of subclinical hypothyroidism in chronic kidney disease. The Journal of the Association of Physicians of India. 2018; 66(7):76-9.

9. Naseem F, Mannan A, Dhrolia MF, Imtiaz S, Qureshi R, Ahmed A. Prevalence of subclinical hypothyroidism in patients with chronic kidney disease on maintenance hemodialysis. Saudi journal of kidney diseases and transplantation: an official publication of the Saudi Center for Organ Transplantation, Saudi Arabia. 2018; 29(4):846-51.

10. Wang K, Xie K, Gu L, Xu B, Chen J, Lou Q, et al. Association of thyroid function with the estimated glomerular filtration rate in a large Chinese euthyroid population. Kidney \& blood pressure research. 2018; 43(4):1075-83.

11. Munoz-Ortiz J, Sierra-Cote MC, Zapata-Bravo E, Valenzuela-Vallejo L, Marin-Noriega MA, Uribe-Reina P, et al. Prevalence of hyperthyroidism, hypothyroidism, and euthyroidism in thyroid eye disease: A systematic review of the literature. Systematic reviews. 2020; $9(1): 201$. 
12. Palit $T$, Heald $A H$, Fryer $A A$, Duff $C J$. Screening for thyroid disease in patients with type 2 diabetes mellitus: An evaluation of current practice. Annals of clinical biochemistry. 2020; 57(3):242-5.

13. Yuasa R, Ohashi Y, Saito A, Tsuboi K, Shishido S, Sakai K. Prevalence of hypothyroidism in Japanese chronic kidney disease patients. Renal failure. 2020; 42(1):572-9.

14. Huang CW, Li BH, Reynolds K, Jacobsen SJ, Rhee $\mathrm{CM}$, Sim JJ. Association between hypothyroidism and chronic kidney disease observed among an adult population 55 years and older. Medicine. 2020; 99(17):e19569.

15. Rosario PWS, Calsolari MR. Impact of subclinical hypothyroidism with $\mathrm{TSH}</=10 \mathrm{mIU} / \mathrm{L}$ on glomerular filtration rate in adult women without known kidney disease. Endocrine. 2018; 59(3):694-7.

16. Cohen L, Pouletty M, Frerot A, Tanase A, Ali L, Baudouin V. Voiding cystography: an unusual route of induced hypothyroidism by iodine overdose in two newborns with chronic kidney disease. Pediatric nephrology. 2019; 34(7):1295-7.

17. Zhu W, Dong X, Pan Q, Hu Y, Wang G. The association between albuminuria and thyroid antibodies in newly diagnosed type 2 diabetes mellitus patients with Hashimoto's thyroiditis and euthyroidism. BMC endocrine disorders. 2020; 20(1):172.
18. Frelau A, Palard-Novello $X$, Jali $E$, Boussemart $L$, Dupuy $A$, James $P$, et al. Increased thyroid uptake on 18F-FDG PET/CT is associated with the development of permanent hypothyroidism in stage IV melanoma patients treated with anti-PD-1 antibodies. Cancer immunology, immunotherapy: CII. 2020:679-687.

19. Grulet H, Barraud S, Chikh K, Souchon PF, Claris O, Bouvier $\mathrm{R}$, et al. Three consecutive pregnancies in a patient with chronic autoimmune thyroid disease associated with hypothyroidism and extremely high levels of anti-thyrotropin receptor antibodies. Thyroid: official journal of the American Thyroid Association. 2019; 29(5):743-7.

20. Srivastava VK, Singh $H$. Association of thyroid peroxidase antibody and dyslipidemia in subclinical hypothyroidism. Journal of family medicine and primary care. $2017 ; 6(1): 63-8$.

21. Shimizu Y, Kawashiri SY, Noguchi Y, Nagata Y, Maeda T, Hayashida N. Anti-thyroid peroxidase antibody and subclinical hypothyroidism in relation to hypertension and thyroid cysts. PloS one. 2020; 15(10):e0240198.

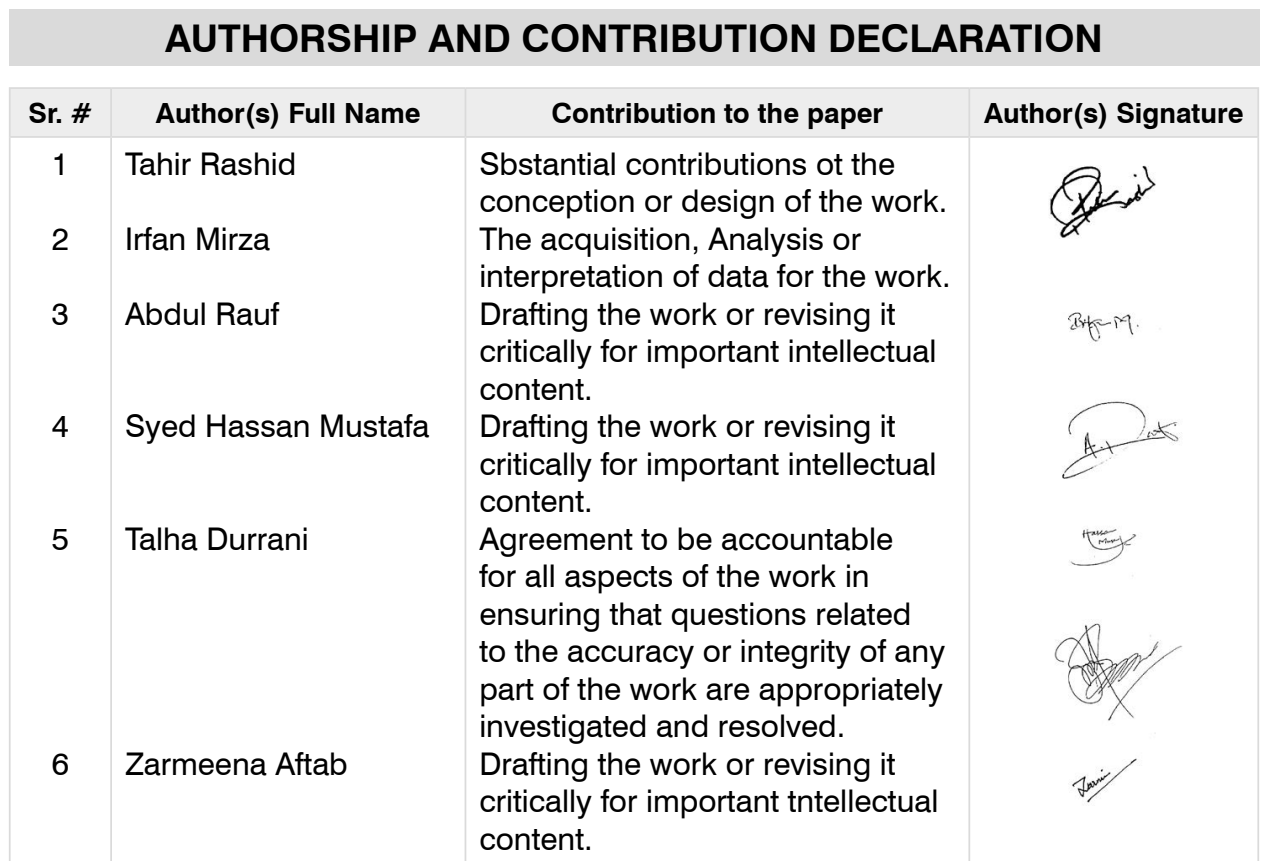

